\title{
Parental Punishment as predictors of stress tolerance and problem solving among their teenage children
}

\author{
Sonia George ${ }^{1}$, Amar Rajan² \\ ${ }^{1}$ Assistant Professor and Head, Department of Psychology, Government College for Women, \\ Thiruvananthapuram, Kerala. \\ ${ }^{2}$ Research Scholar in Psychology, University of Kerala, Thiruvananthapuram, Kerala \\ E-mail-sonia@mindcarter.com \\ Corresponding Author - Dr. Sonia George
}

\begin{abstract}
Background: The present study was intended to find out the relationship between parental punishment and two child variables, viz., problem solving and stress tolerance and also to see if parental punishment acts as a predictor for these two variables. Problem solving and stress tolerance are considered to be positive qualities which would lead to success in life. These qualities can be influenced the level of punishment given by parents to their children.

Methodology: This study was done among 650 teenagers studying in different schools and colleges in Kerala, the southernmost state in India. The tools used in this study were a subscale, Punishment, of the Child-Rearing Practices (CRP) Scale (Student Appraisal Form, Problem Solving Inventory (PSI), and Stress Tolerance Scale. The statistical techniques used were Pearson product-moment correlation and regression analysis.

Results: The results showed that there existed significant correlation between parental punishment and the two child variables. It was also found that paternal punishment predicts stress tolerance and problem solving among their teenage children.

Conclusion: When it comes to teenage students, the punishments given to them by their parents influence their stress tolerance and problem solving.
\end{abstract}

Key words: Parental Punishment, Stress Tolerance, Problem Solving, Teenage, Stress

(Paper received $-10^{\text {th }}$ November 2017, Peer review completed $-20^{\text {th }}$ November 2017)

(Accepted - 20 $0^{\text {th }}$ November 2017)

\section{INTRODUCTION}

The family is a system of interacting individuals who reciprocally socialize and mutually regulate each other. The family environment has a profound role in the development and behavior of children. In time, a child's environment expands to include the effects of a variety of aspects such as culture, subculture, family, school, television, friends, and peers. However the most important influences come from the caregivers. The quality of mothering and fathering is, therefore, of prime importance. Even though other relationships within and outside the family are also influential, a reciprocal parent - child relationship is central to human development. If the home and the parents supply the right environment of study, love and affection, and provide the child with opportunity to express the self in freedom, then like a plant given good soil and sunlight, the child will flourish [1].

Most research in the parent-child area operates on the assumption that there is a discernible relation between parent variables and child variables. Over the years, most developmental psychologists have become increasingly skeptical about studying parent-child interactions through child-rearing practices. 
Based on the findings of particular interactions between parents and children, and between adults and children in general, it is clear that the way that an adult responds to a child's behavior can have a potent effect [2].

Stresses and problems have become an associate of modern and postmodern era of living and management. Accept it or not, stress is there in the personal life of an individual, society, and the organization. Today's techno-commercial age is contrary to man's nature and leads to situations unhealthy and unworthy of human conditionality. These unnatural and unhealthy things destroy the positive substances of man. These imbalances or tendencies to create imbalance lead to stress, which may be accompanied by a diversity of problems [3].

No one can have a life without problems because all things do not happen, smoothly, according to our wish. There come many obstacles when we try to reach a goal. Many factors, environmental, social, and personal, may act as barriers in our way. Under these circumstances, most of us may have a tendency to stop our work. But, if we have to reach our goal and succeed in our life, we have to overcome all these problems. When we are not able to reach our goal smoothly, we are likely to be frustrated. This may lead to stress. This stress is likely to affect the harmony and peace of a person.

If we can effectively withstand or tolerate this stress and solve the problems that come in our way, then we are sure to be in a harmonious and balanced state. Even if we have the ability to solve the problems that come in our way, if we are in a stressful state, we may not be able to utilize our abilities effectively. This shows that both stress tolerance and problem solving ability are essential for a successful life.

Two critical personal resources for dealing with stressors are one's stress tolerance and problem solving skills. How people respond to difficult life problems is an exceedingly complex process and seems to depend on many personal and environmental factors. Some people bring many skills and strengths as to how to approach problems and to reduce the negative effects of the stressful event, whereas others have significant problem solving deficits and low stress tolerance levels [4].

One of the central questions in psychology is how we become the people we are, and it is generally accepted that the experiences that an individual has, go some way towards shaping his attitudes, his outlook on life, his moral values, his relationships with other people and his intellectual development. Common sense, supported by the findings of research, further suggests that the period of childhood is of particular significance in this whole process of character formation, so that the way in which children are brought up is of considerable importance in the formation of the complete adult person. The atmosphere the parents create in the home and the child-rearing methods they use are crucial to normal personality development and significant progress toward socialization [5-6].

Children of today must be reared for living in the world of tomorrow. The world of tomorrow is viewed as more mobile, nationally and internationally; more dynamic, with change being the rule instead of the exception; better educated, as demands for brain power increase; and more democratic, particularly in the equality of sexes. The greatest need is to develop goals for children to live by so that they can develop into more fully functioning human beings [7].

Parents show a variety of behavior patterns to their children and all of those behaviors have a tremendous effect on the child. Punishment is one such variable. The term punishment refers to that which causes someone who has done something wrong or committed a crime to suffer. The Oxford Dictionary of Psychology defines punishment as any stimulus that an organism seeks to avoid or escape [5]. There are many situations when parents get irritated by what their children do. Sometimes children do not obey their parents. In such situations, most parents punish their children and this punishment can take many different forms like scolding, beating, withdrawing positive things, not giving attention etc. Parents also differ in the degree to which they punish their children. Even the same level of punishment may have different effects on different children. So, it is very important that parents perfectly understand their children and their situation, before giving them any sort of punishment, as even a slight punishment may have a great effect on the children. Children should know why they are punished and what behavior is expected from them. Only then, punishment will yield a positive result as all the parents expect [8]. A number of investigators reported a positive correlation between physical punishment and aggression in the child. 
Ayer and Bernreuter [9] reported a study of the personality traits of nursery school children in relation to their home discipline. Significant correlations appeared between physical punishment at home and a tendency of children not to face reality and between permissiveness of parents and a more attractive personality in the child. Sears and associates [10], studying nursery school children, reported a positive relationship between severity of maternal punishment and aggression in boys. Vasta and others [11] found that authoritarian parents who set strict limits on their children's behavior and enforced them with anger and punishment had children who tended to be more cognitively and socially competent than children of other parents.

Whatever punishment parents gave, its severity depended on how it was perceived by the children. Sometimes a mild behavior on the part of parent given as punishment might have very severe effect on the child and vice versa. This perception of the parents' behavior was sure to affect the personality and behavior pattern of children. The aim of the present study is to find out how this happens in the case of stress tolerance and problem solving of the children.

\section{METHODOLOGY}

\section{Sample}

The present study aimed at studying the teenagers in Kerala and their perception of their parents' rearing styles. The population included teenage students from different schools and colleges of Kerala. A total of 820 students were approached for the study. The final sample selected included only 650 students as the remaining 170 either did not belong to the teenage group or gave incomplete response sheets. The sample selected includes 650 students from class 7 to first year Degree class. According to Kerlinger [12], a sample of 600 to 700 individuals or families can have a remarkably accurate measure of a community, its values, attitudes, and beliefs. Stratified sampling had been used to select the sample for the investigation.

The sample for the study was drawn from different schools and colleges in three districts of Kerala viz. Thiruvananthapuram, Alappuzha and Kottayam. School and college going teenagers were selected from institutions in both urban and rural areas which included males and females belonging to the age group from thirteen to nineteen years. Students belonged to the three religious groups, Hindu, Christian, and Muslim. Students also differed in their place of stay, socio-economic status, order of birth, religion, and also in the number of siblings they had. Thus a total of 650 teenage students could be included in the present study. The population of the study consisted of teenage students in Kerala.

\section{Tools}

The present investigation focused mainly on three variables, namely, child rearing practices, stress tolerance, problem solving, and hence it required tools to measure the three variables. Child Rearing Practices Scale [13] (Student Appraisal Form) was constructed for the present investigation to measure the punishment (B) given by parents as perceived by the children. Stress Tolerance Scale [14] measured the Stress Tolerance of the students and Problem Solving Inventory (PSI) [15] measured the problem solving ability of the subjects. Stress Tolerance Scale measured the stress tolerance of the students and Problem Solving Inventory (PSI) measured the problem solving ability of the students. The sub variables of problem solving included Problem Solving Confidence denoted as PSC, Approach Avoidance Style denoted as AAS, and Personal Control denoted as PC. The total score of problem solving was calculated by adding the score of the three sub variables and was named as Problem Solving Total (PST).

\section{Child Rearing Practices Scale}

The first step for the construction of the CRP scale involved item preparation. The items for the sub variable Punishment was prepared by referring to literature, definitions, related studies and other psychological tests which had direct and indirect relevance with present test. Self-descriptive statements were used as items, as it was expected that it would provide a good measurement of variables. The statements described the different ways in which father and mother interacted with their children. All the items were written in English and also translated into the regional language (Malayalam) for the convenience of the students. The draft scale contained 20 items. The statements were prepared in such a 
way that the subject could respond on a 5-point scale by giving strongly agree, agree, undecided, disagree, and strongly disagree as answers. The instructions, which were also given in English and Malayalam, preceded the items. A score of 5 was given if the response was strongly agree, a score of 4 if the response was agree, 3 if the response was undecided, 2 if the response was disagree and 1 if the response was strongly disagree. This scoring pattern was followed if the item was a positive statement. for a negative item, the scores were in the reverse order. Regarding the omission of items, a response sheet was not scored if there were three or more omitted items or items to which no responses are made. If there were only one or two omitted items, a score of 3 was given for each item.

The interpretation of the concept of the subscale Punishment of the Child Rearing Practices Scale is given below. The term punishment refers to that which causes someone who has done something wrong or committed a crime to suffer. There are many situations when parents get irritated by what their children do. Sometimes children do not obey their parents. In such situations, most parents punish their children and this punishment can take many different forms like scolding, beating, withdrawing positive things, not giving attention etc. Parents also differ in the degree to which they punish their children. Even the same level of punishment may have different effects on different children. Whatever punishment parents gave, its severity depended on how it was perceived by the children. Sometimes a mild behavior on the part of parent given as punishment might have very severe effect on the child and vice versa. This perception of the parents' behavior was sure to affect the personality and behavior pattern of children.

The items were prepared in such a way that not giving punishment was considered as measuring the variable (positive items) and giving punishment was considered as the opposite of the study variable (negative items). A couple of sample items in this section are given below.

1. My father/mother punishes me on my failures

2. My father/mother does not punish me severely.

Item analysis was done to select the most suitable items from the draft scale, for inclusion in the final scale. Eight (8) items were selected for the final form, by including those items which had relatively high discriminatory power and having moderate difficulty level. The items having high discriminatory index and those having medium level of discriminatory indices were selected for the final scale.

The validity of the scale was established using face validity, content validity, and concurrent validity. The internal consistency (odd-even reliability) of the subscale was calculated using Spearman-Brown formula. The odd-even reliability of the tool for the standardization sample was found to be 0.801 .

\section{The Problem Solving Inventory}

The problem solving Inventory or PSI assessed perceptions of one's problem solving ability as well as behaviors and attitudes associated with problem solving style. The inventory did not assess actual problemsolving skills but rather one's perception of one's problem-solving beliefs and style. The PSI consisted of 35 items, including 3 filler items. The instructions define problems as personal problems that many people experience, such as depression, inability to get along with friends, or deciding whether to get a divorce. The initial exploratory factor analysis [16] suggested three factors within the PSI: a) Problem Solving Confidence (PSC, 11 items), b) Approach-Avoidance Style (AAS, 16 items), and c) Personal Control (PC, 5 items); the PSI total score was the sum of these three subscales. Each factor provided an appraisal of a specific dimension of one's problem solving style, and the total score reflected an individual's overall appraisal of his or her problem solving style. Score for all three factors and the total PSI were continuous rather than categorical scores. Perceived effective and ineffective problem solvers were operationalized as those who scored toward one end versus the other end of the continuous range of PSI scores. Problem Solving Confidence (PSC) was defined as an individual's self-assurance, beliefs, and trust in his or her ability to effectively cope with a wide range of problems. Approach-Avoidance style (AAS) referred to a general tendency to approach or avoid different problem-solving activities. Personal Control (PC) was defined as believing one is in control of one's emotion and behaviors while solving problems.

The PSI had been found to have acceptable internal consistency estimates across a number of populations and cultures [15-16]. Summing across studies, the PSI total obtained average alpha coefficients in the high $.80 \mathrm{~s}$, whereas two of the factors (PSC and AAS) obtained average alpha coefficients in the low to mid $.80 \mathrm{~s}$, and the third factor (PC) obtained average alpha coefficients in the low 0.7. These results suggested that 
the PSI is internally consistent and a range of studies provided a wealth of data supporting the validity of the PSI [17].

\section{The Stress Tolerance Scale}

The Stress Tolerance Scale was constructed by Resmi and Sananda Raj, (Department of Psychology, University of Kerala) in the year 1999 [18]. The scale development was started by collecting definitions through an extensive review of the relevant literature. After getting a clear idea of the various aspects and dimensions of stress tolerance, a set of 44 items were prepared covering the different aspects related to stress tolerance. After consulting with the experts, 14 items were dropped out (having least face validity). Thus in the draft scale there were 30 items. It was also ensured that the test contained equal number of positive (Favourable) and negative (Unfavourable) items. Each item in the draft scale was presented in English and Malayalam. There were five response choices corresponding to each item in the draft scale, Strongly Agree (A), Agree (B), Undecided (C), Disagree (D) and Strongly Disagree (E). The individual response was to be made by making a $\checkmark$ mark against the answer they selected. There were positive and negative items in the scale. For a positive item, a weightage of 5, 4, 3, 2 and 1 was awarded for A, B, C, D and $\mathrm{E}$ respectively, and for a negative item the weightage was reversed as 1, 2, 3, 4 and 5 respectively. The score for each item was entered on the response sheet. Then by summing up the responses, total score was taken for each subject. The test was administered to a sample of 350 individuals for the purpose of item analysis. "Mathew Item Analysis Table", was used for Item Analysis. 24 items were found suitable to be included in the main scale. Final form consisted of equal number of positive and negative items. The reliability of the whole test was found out using Spearman Brown formula. Thus a reliability coefficient of 0.82 was obtained. This index of reliability shows that Stress Tolerance Scale is highly reliable. This value of reliability is significant at 0.01 level. The validity of the test was estimated with the help of empirical or criterion related validity. It was found out by correlating the present scale with "Stress Tolerance Inventory" of Asha Balagangadharan, 1998 [19]. Both the tests were administered to a sample of 40 subjects and the correlation coefficient was estimated as 0.72 . This index of validity showed that Stress Tolerance Scale is adequately valid. This value was significant at 0.01 level.

\section{Data Collection Procedure}

Data was collected from the different schools and colleges of Kerala using the three scales. The tools were given one at a time, and it took an average of one hour to complete one set of tools. A total of 820 data were collected, from which 170 had to be discarded for various reasons. The tests were scored to get the values of each variable under study.

\section{STATISTICAL ANALYSIS}

All the variables were assigned numbers or values and were entered into the computer. Then the data were subjected to statistical analysis with the help of a computer using a specific program. The statistical techniques selected with respect to the objective of the study included correlation analysis and regression analysis.

\section{RESULTS AND DISCUSSION}

The aim of the study was to see whether and how the punishment given by the parents influences the stress tolerance and problem solving of their children. This first involved finding the relationship between the three main variables. Table 1 exhibits how the variable Punishment was related to stress tolerance and problem solving of their children. Punishment is perceived by children in terms of both father and mother. Thus the variable Punishment (B) is in two forms, indicating the punishment given by father (CRBF) and mother (CRBM). 
Table 1: Correlation of Stress Tolerance, Problem Solving, and Punishment

\begin{tabular}{|l|l|l|l|l|l|l|}
\hline Variables & & ST & PSC & AAS & PC & PST \\
\hline CRBF & Correlation & $.120^{* *}$ & $.158^{* *}$ & .076 & -.024 & $.155^{* *}$ \\
& Sig.(2-tailed) & .002 & .000 & .054 & .535 & .000 \\
& $\mathrm{~N}$ & 650 & 650 & 650 & 650 & 650 \\
\hline CRBM & Correlation & .006 & .025 & .046 & -.068 & .038 \\
& Sig.(2-tailed) & .886 & .532 & .241 & .082 & .333 \\
& $\mathrm{~N}$ & 650 & 650 & 650 & 650 & 650 \\
\hline \multicolumn{7}{|c}{ ** Correlation is significant at the 0.01 level (2-tailed). } \\
\hline
\end{tabular}

Punishment was found to have significant positive correlation with stress tolerance, problem solving confidence and the total score for problem solving, but only with respect to father. Mother's punishment was not found to have any significant impact on the child's stress tolerance or problem solving ability. The correlation of father's punishment with stress tolerance, problem solving confidence and problem solving total was significant at 0.01 level. The correlation between CRBF and ST is 0.120 , that between CRBF and PSC is 0.158 and that between CRBF and PST is 0.155 . Even though these correlations are significant at 0.01 level, the correlation coefficients are low. Father's non-punishing behavior was found to be more influential than mother's non-punishing behavior.

When someone feels that they will not be punished for what they do, it gives them a motivation to face the problems that come their way. If you have a feeling that you will be punished if you will not be able to solve the problem correctly then that feeling itself will take away the confidence that you have in you. This, in turn, will also have a negative effect on your problem solving ability. When you have a feeling that you will not be punished if you do things in the wrong way, you will have more confidence in solving a problem and this in turn will increase your problem solving ability. Children will feel like getting into different activities if they perceive their parents as supportive. If parents are perceived as punishing and demotivating, children will always hesitate to do things. Their behavior might show some sort of withdrawal arising from the fear of being punished. Not punishing the children for their deeds, takes away this fear from the children which may motivate these children to be more involved in many activities. Such an involvement might give the child many opportunities to deal with many problems and face many stresses.

Carson, Butcher and Mineka [20] points out that, in the past, discipline was conceived of as a method for both punishing undesirable behavior and preventing or deterring such behavior in the future. Discipline is now thought more positively as providing needed structure and guidance for promoting a child with schemes similar to outcomes actually meted out by the world, contingent on a person's behavior. But still, punishment is viewed as negative, as in the present study, because parents may not make clear exactly what behavior is considered appropriate and also what behavior is expected. Carson, Butcher and Mineka [20] stresses the fact that a child should be allowed independence in keeping with his or her level of maturity, which is when punishments for directing the behavior are not given.

Since it is found that there exists significant relationship among father's punitive behavior and child's stress tolerance and problem solving, we can see if punishment acts as a predictor for these two child variables. For this, regression analysis was done. In the same way, regression analysis was done for all the variables of problem solving, namely, problem solving confidence, approach-avoidance style, personal control and problem solving total. The results are given in tables $2,3,4,5$, and 6 .

It is seen that punishment acts as a predictor variable only for stress tolerance and not for problem solving. This is clear from the significance values in the above tables, where only table 2 gives a significance value of .01, and all other values insignificant. It is only in the case of father that punishment is acting as a predictor. This shows how important a variable is father's non punishing behaviour when it comes to a child's stress tolerance. It is high time that fathers resort to ways other than punishment for dealing with their children, to make them more stress tolerant 
Table 2: Unstandardized and Standardized coefficients associated with punishment as predictor variable of stress tolerance

\begin{tabular}{|c|c|c|c|c|c|}
\hline \multirow{2}{*}{ Model } & \multicolumn{2}{|c|}{ Unstandardized Coefficients } & $\begin{array}{c}\text { Standardised } \\
\text { Coefficients }\end{array}$ & \multirow{2}{*}{$\mathrm{t}$} & \multirow{2}{*}{ Sig. } \\
\cline { 2 - 4 } & $\mathrm{B}$ & Std. Error & Beta & & \\
\hline CrBF & .210 & .081 & .124 & 2.600 & .010 \\
CrBM & -.015 & .021 & -.028 & -.726 & .468 \\
& & & & & \\
\hline
\end{tabular}

Table 3: Unstandardized and Standardized coefficients associated with the predictor variables of problem solving confidence

\begin{tabular}{|c|c|c|c|c|c|}
\hline \multirow{2}{*}{ Model } & \multicolumn{2}{|c|}{ Unstandardized Coefficients } & $\begin{array}{c}\text { Standardised } \\
\text { Coefficients }\end{array}$ & \multirow{2}{*}{$\mathrm{t}$} & \multirow{2}{*}{ Sig. } \\
\cline { 2 - 4 } & $\mathrm{B}$ & Std. Error & Beta & & \\
\hline $\mathrm{CrBF}$ & .084 & 0.47 & -.030 & 1.773 & .077 \\
$\mathrm{CrBM}$ & -.010 & .012 & .063 & -.795 & .427 \\
\hline
\end{tabular}

Table 4: Unstandardized and Standardized coefficients associated with the predictor variables of approach avoidance style

\begin{tabular}{|c|c|c|c|c|c|}
\hline \multirow{2}{*}{ Model } & \multicolumn{2}{|c|}{ Unstandardized Coefficients } & $\begin{array}{c}\text { Standardised } \\
\text { Coefficients }\end{array}$ & \multirow{2}{*}{$\mathrm{t}$} & \multirow{2}{*}{ Sig. } \\
\cline { 2 - 4 } & $\mathrm{B}$ & Std. Error & Beta & & \\
\hline CrBF & .034 & .062 & .026 & .554 & .580 \\
CrBM & .006 & .082 & .014 & .364 & .716 \\
\hline
\end{tabular}

Table 5: Unstandardized and Standardized coefficients associated with the predictor variables of personal control

\begin{tabular}{|c|c|c|c|c|c|}
\hline \multirow{2}{*}{ Model } & \multicolumn{2}{|c|}{ Unstandardized Coefficients } & $\begin{array}{c}\text { Standardised } \\
\text { Coefficients }\end{array}$ & $\mathrm{t}$ & \multirow{2}{*}{ Sig. } \\
\cline { 2 - 4 } & $\mathrm{B}$ & Std. Error & Beta & & \\
\hline CrBF &. .025 & .024 & -.050 & -1.029 & .304 \\
CrBM & .011 & .001 & .069 & 1.748 & .081 \\
\hline
\end{tabular}

Table 6: Unstandardised and Standardized coefficients associated with the predictor variables of problem solving total

\begin{tabular}{|c|c|c|c|c|c|}
\hline \multirow{2}{*}{ Model } & \multicolumn{2}{|c|}{ Unstandardized Coefficients } & $\begin{array}{c}\text { Standardised } \\
\text { Coefficients }\end{array}$ & \multirow{2}{*}{$\mathrm{t}$} & \multirow{2}{*}{ Sig. } \\
\cline { 2 - 4 } & $\mathrm{B}$ & Std. Error & Beta & & \\
\hline $\mathrm{CrBF}$ & .198 & .107 & .088 & 1.845 & .065 \\
$\mathrm{CrBM}$ & -.015 & .028 & -.021 & -.533 & .594 \\
\hline
\end{tabular}

\section{CONCLUSIONS}

It is of no doubt that a strong foundation is necessary for any building. Same is the case with the child rearing practices. The foundation on which a child's personality and behaviour are built, need to be good and strong, and this is undoubtedly the duty of the parents. From the [present study, it could be found that 
the punishment given by father is sure to have a significant role in the building up of positive qualities in a child. This investigation scientifically proves that the punishment given by the father is related to both stress tolerance and problem solving in children. Furthermore, fathers' punishment was found to act as a predictor of stress tolerance in a teenage child. This result can provide information to parents and counselors regarding how to make a child tolerant to stress and to equip them to solve their problems. Children may also be given guidance to modify their lifestyle, if the parenting style is felt insufficient for the development of such capacities.

The scale constructed for the present study may be used by parents for getting feedback regarding their behavior towards their children. When parents know how their behaviors are perceived by their children, they can improve upon those factors which need improvement. Another important implication of the study is regarding providing training to parents and prospective parents on how to bring up their children in a good way, i.e., by imbibing positive qualities in them. Training modules can be developed based on the sub variables of the scale, and also based on the results of the study. Training can be given to groups of parents, prospective parents, and child caregivers, and this will surely lead to a better tomorrow.

\section{REFERENCES}

1. Lugo JO, Hershey GL. Living psychology: Research in action. Macmillan; 1976.

2. Tilker HA. Developmental psychology today. New York. Random House ; 1975.

3. Compas BE, Howell DC, Phares V, Williams RA, Giunta CT. Risk factors for emotional/behavioral problems in young adolescents: A prospective analysis of adolescent and parental stress and symptoms. $\mathrm{J}$ Consult Clin Psychol 1989;57(6):732-40.

4. Davis GA. Psychology of problem solving: Theory and practice. Basic Books (AZ); 1973.

5. Thibaut JW, Spence JT, Carson RC, Brehm JW. Contemporary topics in social psychology. General Learning Press; 1976.

6. Heider F. The psychology of interpersonal relations. Psychology Press; 2013.

7. Bettelheim B. A good enough parent: A book on child-rearing. Vintage; 1988.

8. Welsh RS. Severe parental punishment and delinquency: A developmental theory. J Clin Child Adolesc Psychol 1976;5(1):17-21.

9. Ayer ME, Bernreuter RA. A study of the relationship between discipline and personality traits in young children. J Gen Psychol 1951;50:165-70.

10. Sears RR, Whiting JWM, Nowlis V, Sears PS. Some child-rearing antecedents of aggression and dependency in young children. Genetic Psychol Monogr 1953;47:135-234.

11. Vasta R, Haith MM, Miller SA. Child psychology: The modern science. John Wiley \& Sons; 1992.

12. Kerlinger FN. Foundations of behavioral research.Holt Reinhart and Wilson ; 1986.

13. Rickel AU, Biasatti LL. Modification of the block child rearing practices report. J Clin Psychol 1982;38(1):129-34.

14. Welle PD, Graf HM. Effective lifestyle habits and coping strategies for stress tolerance among college students. Am J Health Educn 2011;42(2):96-105.

15. Heppner PP, Petersen CH. The development and implications of a personal problem-solving inventory. J Couns Psychol 1982;29(1):66-78.

16. Maydeu-Olivares A, D'Zurilla TJ. A factor-analytic study of the Social Problem-Solving Inventory: An integration of theory and data. Cogn Ther Res 1996;20(2):115-33.

17. Sahin N, Sahin NH, Heppner PP. Psychometric properties of the problem solving inventory in a group of Turkish university students. Cogn Ther Res 1993;17(4):379-96.

18. Resmi CS, Sananda Raj HS. Stress Tolerance Scale. Thiruvananthapuram: Department of Psychology, University of Kerala ; 1999.

19. Asha B. An analytical study of the psychological factors causing coronary heart diseases. Ph.D thesis, University of Kerala ; 1998.

20. Carson RC, Butcher JN, Mineka S. Abnormal psychology and modern life. Needham Heights, MA: Allyn \& Bacon; 2000.

Acknowledgements - Nil ; Conflict of Interest - Nil; Funding - Nil

$* * * * * * * * * * * * * * * * * * * * * *$ 